\title{
The Neo-Tectonic Structure of the Southwestern Tip of the Okinawa Trough
}

\author{
Chia-Yen $\mathrm{Ku}^{1}$, Shu-Kun $\mathrm{Hsu}^{1,}{ }^{*}$, Jean-Claude Sibuet ${ }^{2}$, and Ching-Hui Tsai ${ }^{1}$ \\ ${ }^{1}$ Institute of Geophysics, National Central University, Jhongli, Taiwan, ROC \\ ${ }^{2}$ Institute of Applied Geosciences, National Taiwan Ocean University, Keelung, Taiwan, ROC
}

Received 21 November 2007, accepted 1 September 2008

\begin{abstract}
The Ilan Plain is located at the southwestern tip of the Okinawa Trough backarc basin, which propagates westward into the Taiwan orogen. From three moderate earthquakes which occurred near the coastline of the Ilan Plain, one of magnitude 6.2 on 15 May 2002 and the other two of magnitudes 5.51 and 5.49 on 5 March 2005, we attempted to understand the relationship between the earthquake mechanisms and the geological context. Seven seismic reflection profiles collected roughly parallel to the coastline of the Ilan Plain were used in this work. A structural fault, with a significant normal faulting component trending approximately ENE-WSW, is identified to the east of the doublet earthquakes of 5 March 2005. Because this fault follows the ENE-WSW trend of the aftershock seismicity, we named it the Ilan Shelf Fault, which might extend to the east beyond the Ilan continental shelf spur. However, the centroid seismic moment tensor solutions for the doublet earthquakes of 5 March 2005 are of a left-lateral strike-slip faulting type which are consistent with onland GPS observations. Hence, the Ilan Shelf Fault may have a left-lateral strike-slip component. Based on GPS data, we suggest that the northern Central Range block, bounded in the west by the Lishan Fault and in the north by the Ilan Shelf Fault, rotates clockwise. This rotation is ascribed to the northwestward collision of the Luzon Arc against Taiwan. Thus, there is a left-lateral strike-slip and an extensional motion along the Ilan Shelf Fault. The northern Central Range block is tilting northward which may also induce the normal faulting component of the Ilan Shelf Fault. In short, the Ilan Shelf Fault could be a major tectonic and structural feature bounding the southern end of the Okinawa Trough backarc basin.
\end{abstract}

Key words: Okinawa Trough, Seismic reflection, Ilan Plain, Ilan Shelf Fault, Seismicity

Citation: Ku, C. Y., S. K. Hsu, J. C. Sibuet, and C. H. Tsai, 2009: The Neo-tectonic structure of the southwestern tip of the Okinawa Trough. Terr. Atmos. Ocean. Sci., 20, 749-759, doi: 10.3319/TAO.2008.09.01.01(Oc)

\section{INTRODUCTION}

The Ryukyu trench-arc-backarc system results from the N $309^{\circ}$ convergence and subduction of the Philippine Sea plate with respect to the Eurasian plate, while the Taiwan orogen results from the collision between the Luzon Arc and the Eurasian continental margin. The Okinawa Trough backarc basin extends from the Kyushu Island (Japan) to the Ilan Plain (Taiwan) and by extension has been created within the Eurasian continental lithosphere (e.g., Lee et al. 1980; Sibuet et al. 1987; Sibuet et al. 1998). The last two phases of the opening of the southwestern Okinawa Trough occurred during the Pleistocene (2 - $0.1 \mathrm{Ma})$ and Pleistocene-Holocene (0.1 - 0 Ma) (Sibuet et al. 1998). The recent extension

\footnotetext{
* Corresponding author

E-mail:hsu@ncu.edu.tw
}

phase $(0.1-0 \mathrm{Ma})$ is demonstrated by numerous $\mathrm{E}-\mathrm{W}$ trending normal faults dipping toward the Okinawa Trough axis with a few meters to a few tens meters vertical offsets in the western Okinawa Trough (Sibuet et al. 1998), which turns to ENE-WSW trending normal faults in the westernmost part of the trough (Fig. 1). The morphology and distribution pattern of the normal faults reflect that the westward propagation of the southwestern Okinawa Trough has extended into the Ilan Plain (Sibuet et al. 1998; Wang et al. 2000). Recent alluvial deposits carried by the Lanyanghsi River and accumulated in the Ilan Plain hide the surficial expression of the normal faults. Two seismic reflection and refraction profiles collected across the Ilan Plain by the Chinese Petroleum Corporation (CPC) indicate that ENEWSW faults are present beneath the sedimentary cover of 


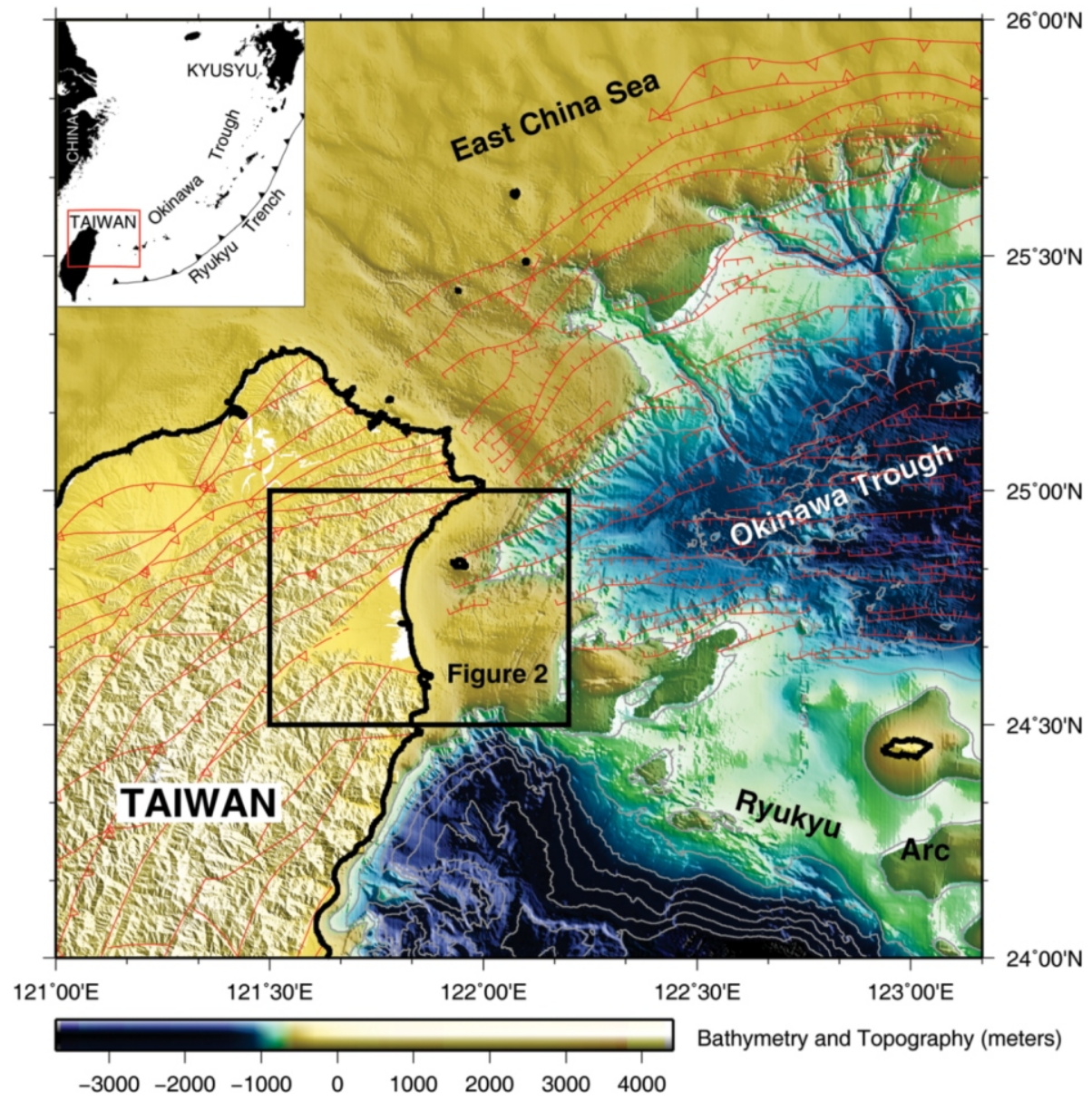

Fig. 1. Bathymetric and structural map of the southwestern Okinawa Trough with contours every 500 meters. The active tectonic features are from Sibuet et al. (1998) and Deffontaines et al. (2001). Onland lines are active faults. Lines with triangles are active thrust faults, lines with perpendicular short segments are active normal faults.

the Ilan Plain (Chiang 1976) (Fig. 2). The presence of that fault pattern in the Ilan Plain is also indicated by magnetic anomaly analyses (Hsu et al. 1996). In the Ilan Plain, several basement faults have been identified but none have been identified within the sedimentary cover (Chiang 1976). These ENE-WSW faults are also in the prolongation of thrust faults outcropped around the Ilan Plain (Deffontaines et al. 2001). Offshore of the Ilan Plain, Kueishantao Island mainly consists of andesitic rocks (Chen et al. 1995) with a subducted Philippine Sea plate slab component, and it is regarded as the westernmost island of the Ryukyu volcanic front (Sibuet et al. 1998). Seismic tomography indicates that a magma body or partial melting exists beneath the Ilan Plain and has moved upward to the subsurface of Kueishantao Island (Lin et al. 2004). Radiometric dating indicates that the Kueishantao Island was formed in the last 200000 years, and the last eruption was 8000 years ago (Chung et al. 2000).

According to recent seismicity cataloged by the Central Weather Bureau Seismic Network (CWBSN) from 1995 to 2006, earthquakes frequently occurred in the southern por- tion of the Ilan Plain, extending from the northern part of the Central Range to offshore of the Ilan Plain (Fig. 2). On 15 May 2002, an earthquake of a magnitude of 6.2 occurred offshore of the Ilan Plain. Then, on 5 March 2005, two moderate consecutive earthquakes of similar magnitudes $\left(\mathrm{M}_{\mathrm{L}}=5.51\right.$ and $\mathrm{M}_{\mathrm{L}}=5.49$, respectively $)$ and same depths $(19 \mathrm{~km})$, separated only by a time interval of 68 seconds, occurred near the coastline of the Ilan Plain (Fig. 2). According to the centroid moment tensor (CMT) solutions determined by waveform inversion of the Broadband Array in Taiwan for Seismology (BATS) data, the three earthquakes exhibit left-lateral strike-slip motions along E-W planar seismogenic structure (Fig. 2). Because the second event of the 2005 doublet was detected $5 \mathrm{~km}$ west of the first, Liang et al. (2005) suggested that the rupture nucleated in the east and propagated to the west. Their observations indicate a major strike-slip faulting component in the southern Ilan Plain.

In order to better define the structural characteristics in this area and to link geological features to the recorded seismicity, we have collected seven seismic reflection profiles between the Kueishantao Island and the Ilan Plain, roughly 


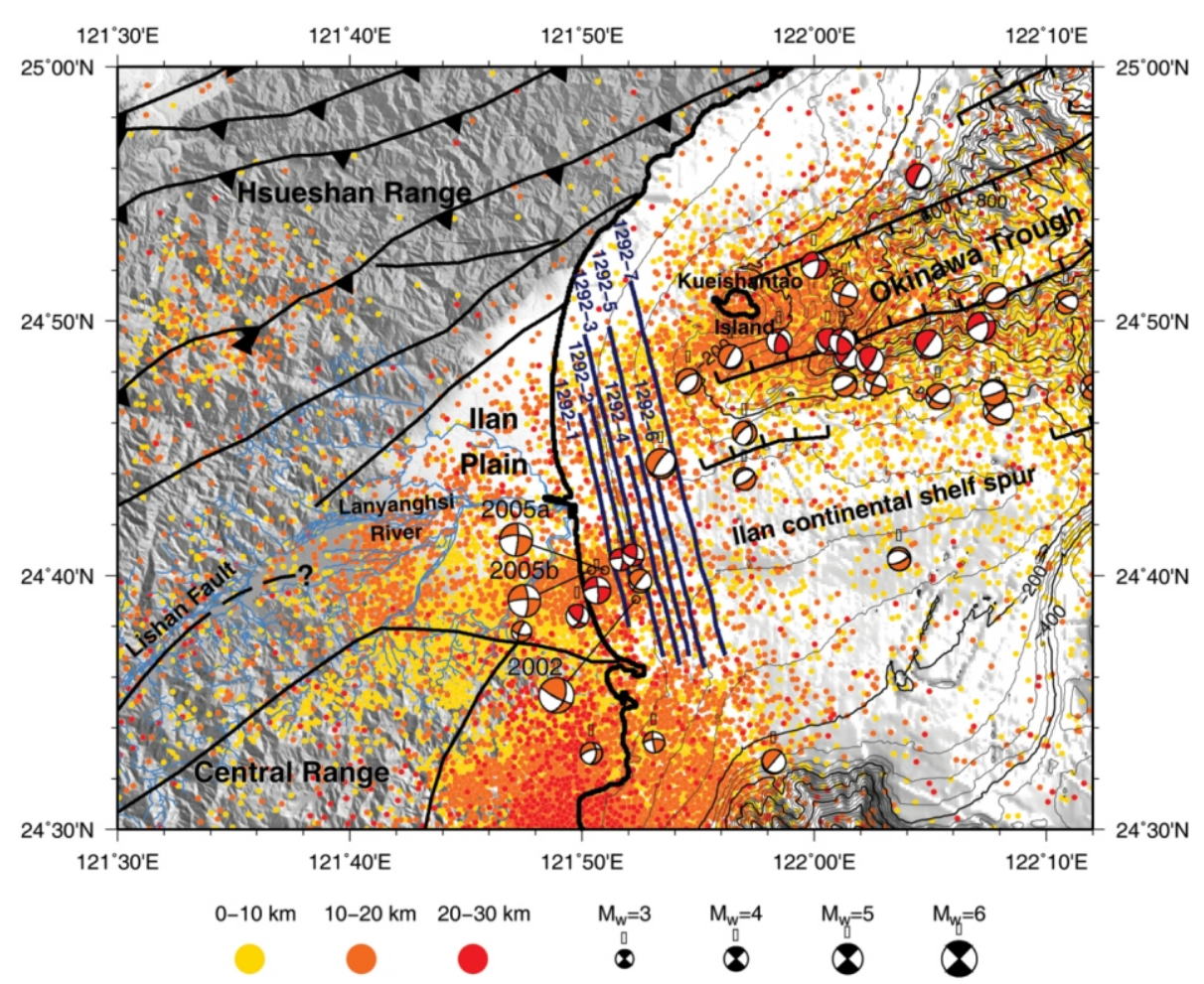

Fig. 2. Structural and seismicity map on the bathymetry background contoured every 50 meters. Dots are locations of short period earthquakes recorded by the Central Weather Bureau (CWB) Seismic Network from 1995 to 2006 . Yellow, orange, and red colors correspond to the depths of the earthquakes. Beach balls are focal mechanisms analyzed from the Broadband Array in Taiwan for Seismology (BATS) from 1995 to 2006. Their sizes are proportional to their respective magnitudes $\mathrm{M}_{\mathrm{W}}$. 2002, 2005a, and b refer to the focal mechanisms of earthquakes occurred on $15 \mathrm{May} 2002$ and 5 March 2005 at 19H06 and 19H07 (GMT), respectively. The thick blue lines are locations of the seven OR2-1292 seismic profiles used in this study. The tectonic features are from Sibuet et al. (1998) and Deffontaines et al. (2001). The two brown lines in the Ilan Plain are the locations of CPC seismic profiles (Chiang 1976). Lines with triangles are active thrust faults; lines with perpendicular short segments are active normal faults and continuous lines are other active faults (Deffontaines et al. 2001).

parallel to the Ilan Plain shoreline (Fig. 2). The aim of this study is to identify the presence of active faults in the nearshore area of the Ilan Plain and to understand the structural geodynamics in this region.

\section{SEISMIC DATA ACQUISITION AND PROCESSING}

Seven high-resolution multi-channel seismic reflection profiles trending in a NNW-SSE direction were collected by using R/V Ocean Researcher 2 (OR2) during the OR2-1292 cruise in June 2005 (Fig. 2). The seismic reflection profiles were designed to be perpendicular to the trend of the southwestern Okinawa Trough normal faults (Sibuet et al. 1998) and the Ilan continental shelf spur, which is a bathymetric ridge protruding eastward to the Ilan continental shelf (Fig. 2). One GI (generator and injector) gun of $45 / 45$ cubic inches was used as the seismic source, which was fired at 10-second intervals with the ship steaming along at a mean speed of 5 knots. Seismic signals were received by a 150 -meter long 12-channel streamer with $3 \mathrm{~s}$ recorded length of data and a $0.5 \mathrm{~ms}$ sampling rate.
All seismic reflection data were filtered with a 10-64$128-256 \mathrm{~Hz}$ band-pass filter. The normal moveout correction and stack were performed using a constant seawater velocity of $1480 \mathrm{~m} \mathrm{~s}^{-1}$. The seven stacked seismic profiles displayed with AGC and their interpretations are shown in Figs. 3 to 9.

\section{SEISMIC INTERPRETATION}

Due to usual fishing activity in the surveyed area and the large width of the Okinawa Trough, it is difficult to realize the full geographical extent of the Okinawa Trough backarc basin. However, three profiles (1292-3, 1292-5, and 1292-7) reasonably covered the northern flank of the backarc basin. We observed that the Okinawa Trough central depression is asymmetrical in the study area with a steep northern flank. In general, the thickness of the sediments in the backarc basin is about $1.3 \mathrm{~km}$ (about $1.7 \mathrm{~s}$ two-way travel time, t.w.t.t.) in the central depression and shallows northward and southward in our study area. The axis of the acoustic basement depression is evident in the northern portion of the profiles. It is located in the prolongation of the westernmost Okinawa 


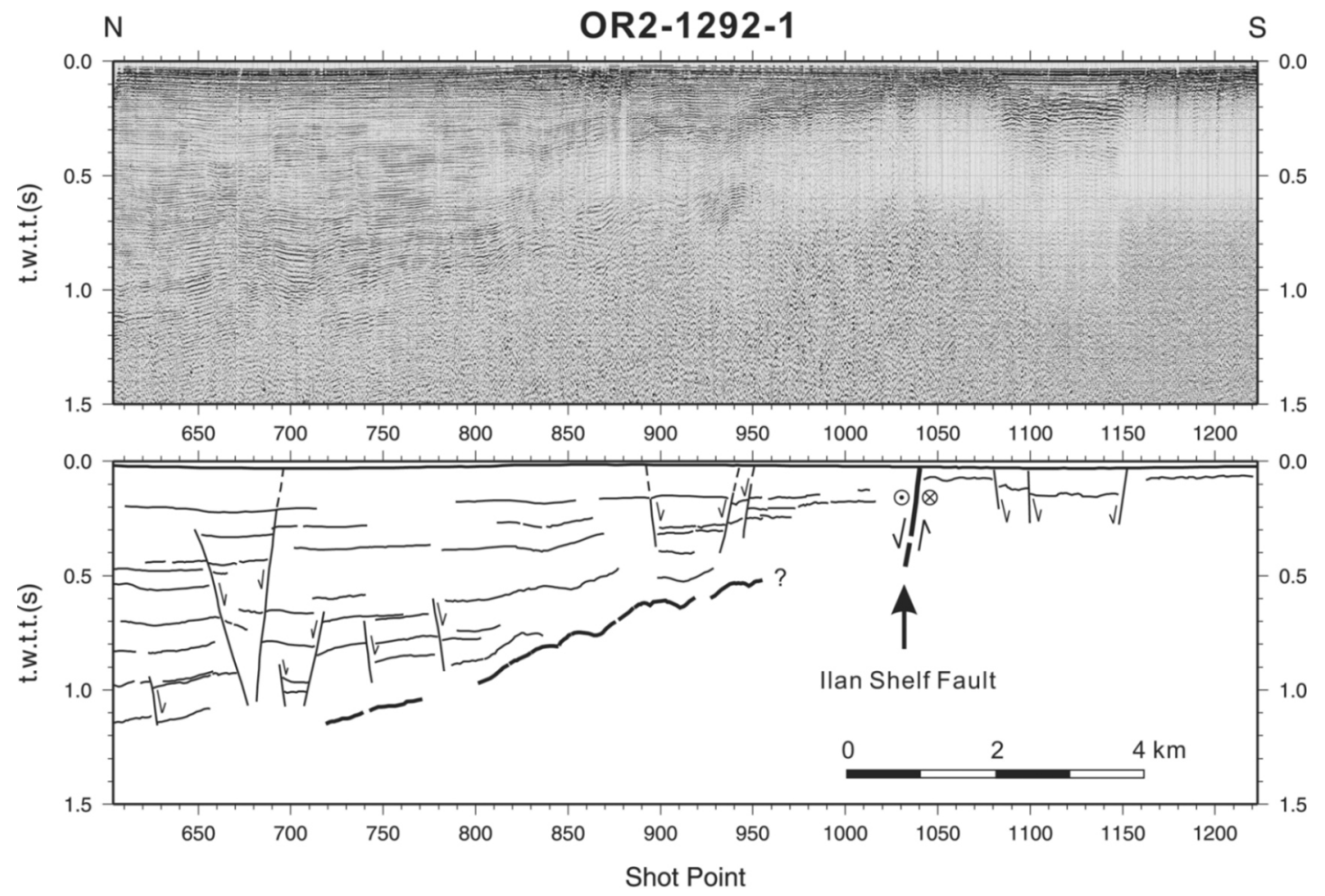

Fig. 3. Stacked 12-channel OR2-1292-1 seismic reflection profile (top) and its interpretation (bottom). See Fig. 2 for location, thin black lines are seismic reflectors and interpreted faults. Thick black lines represent the basement of the Okinawa Trough. t.w.t.t.(s), two-way travel time in seconds.

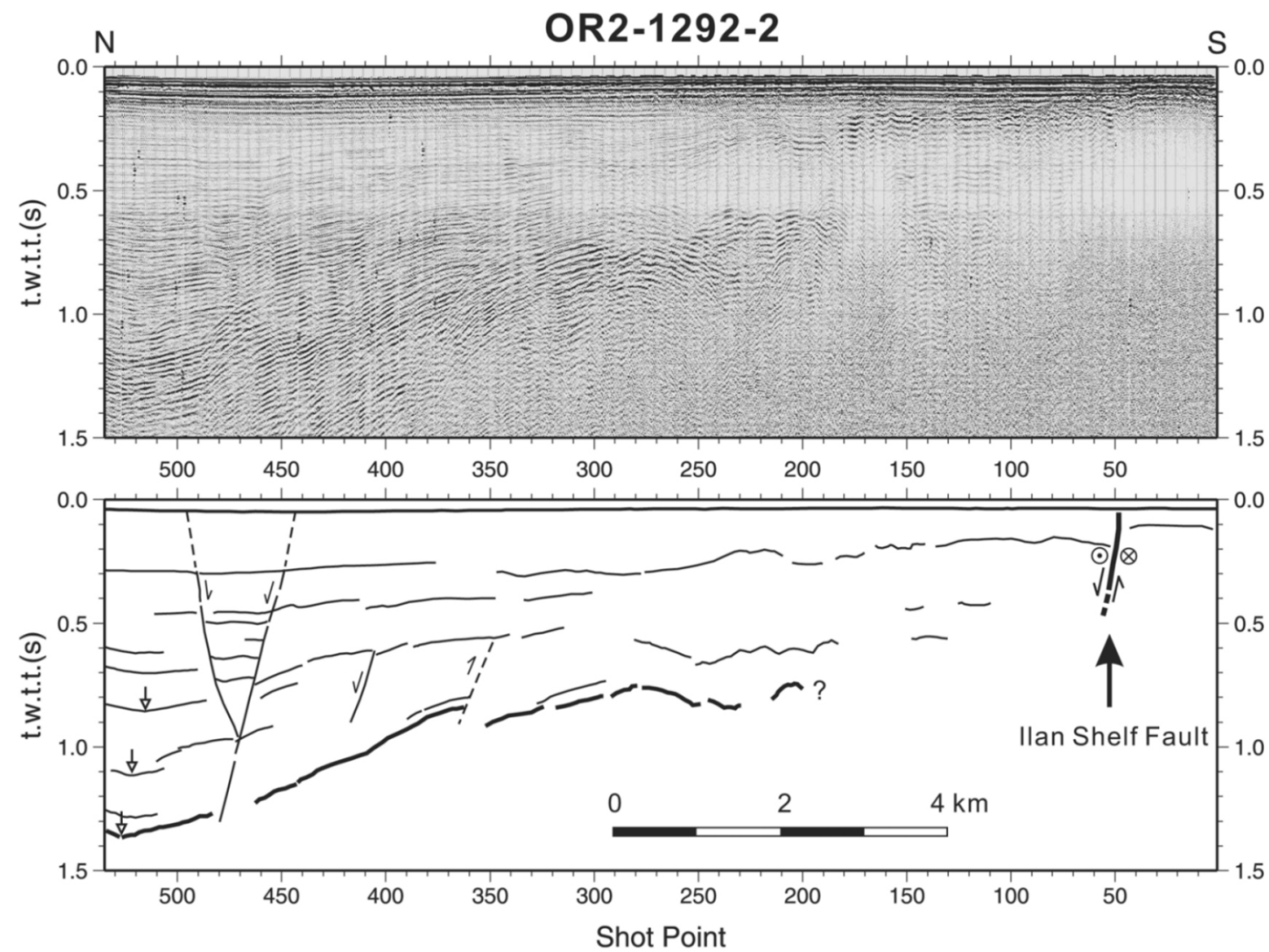

Fig. 4. Stacked 12-channel OR2-1292-2 seismic reflection profile (top) and its interpretation (bottom). White arrows indicate the locations of depocenters at different deposition periods. See Fig. 2 for profile location, other legends are the same as in Fig. 3. 


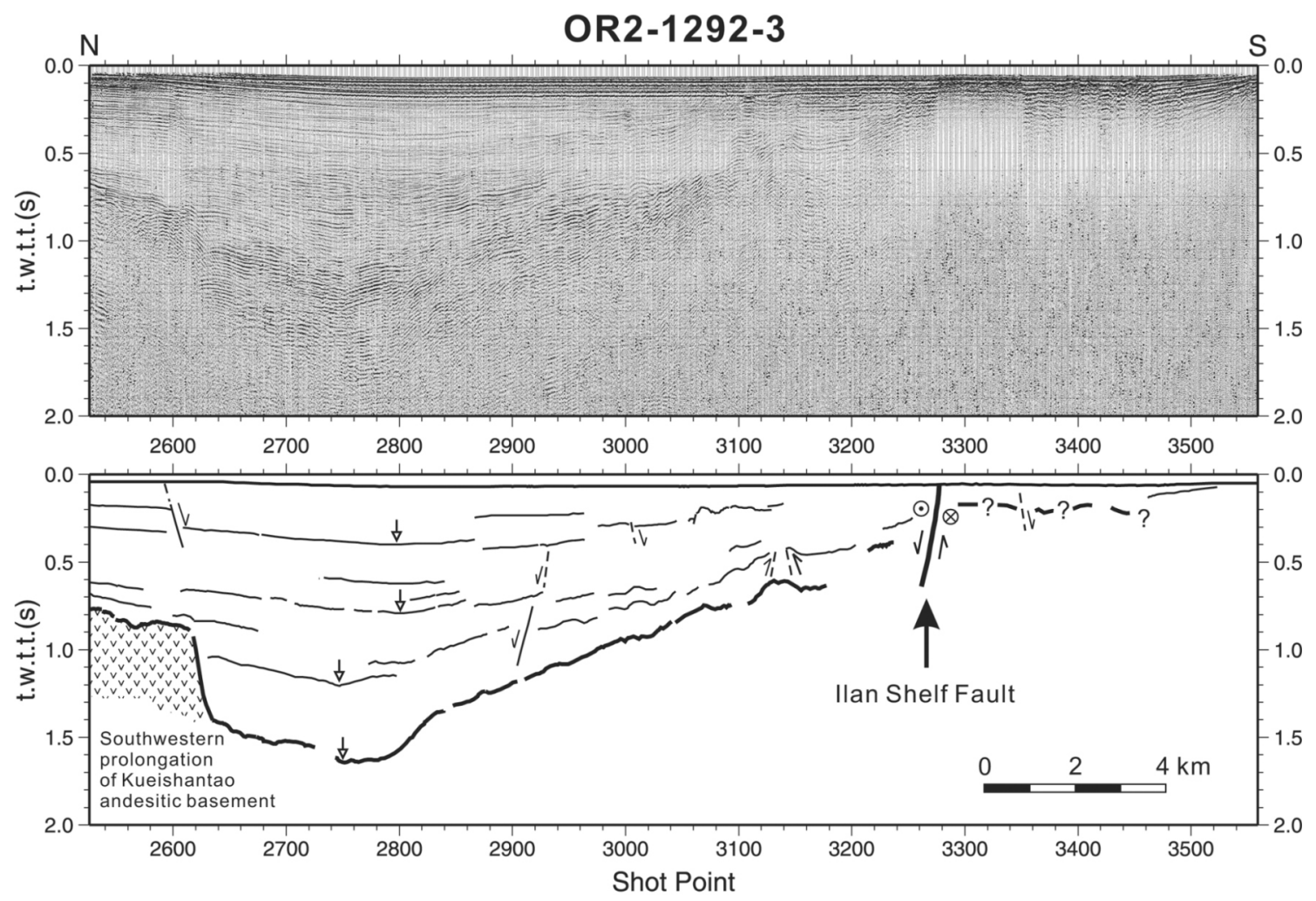

Fig. 5. Stacked 12-channel OR2-1292-3 seismic reflection profile (top) and its interpretation (bottom). The basement in the northern part of the profile corresponds to the southwestern prolongation of the Kueishantao Island acoustic basement. See Fig. 2 for profile location. Same legends as in Figs. 3 and 4.

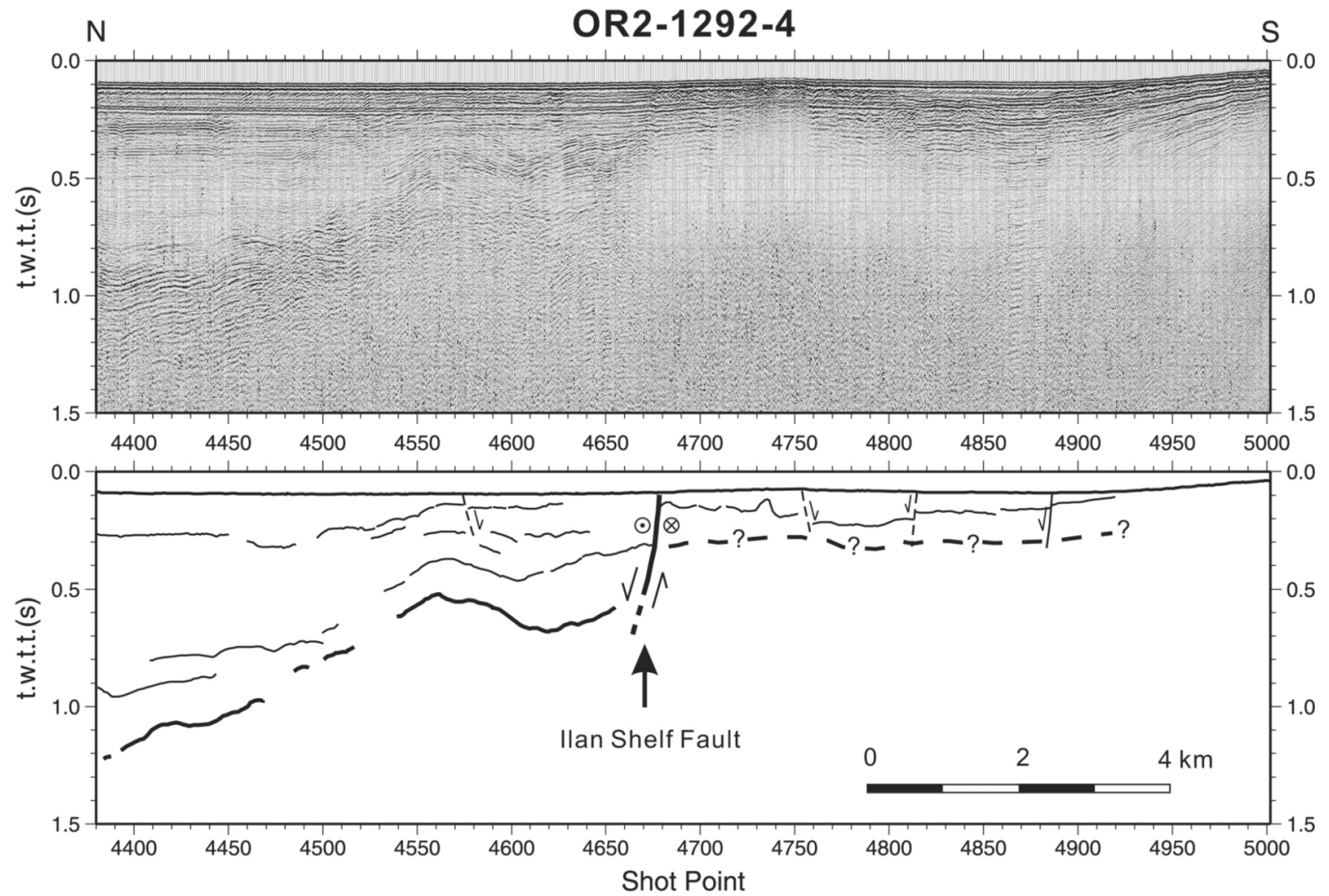

Fig. 6. Stacked 12-channel OR2-1292-4 seismic reflection profile (top) and its interpretation (bottom). Same legend as in Fig. 3. 


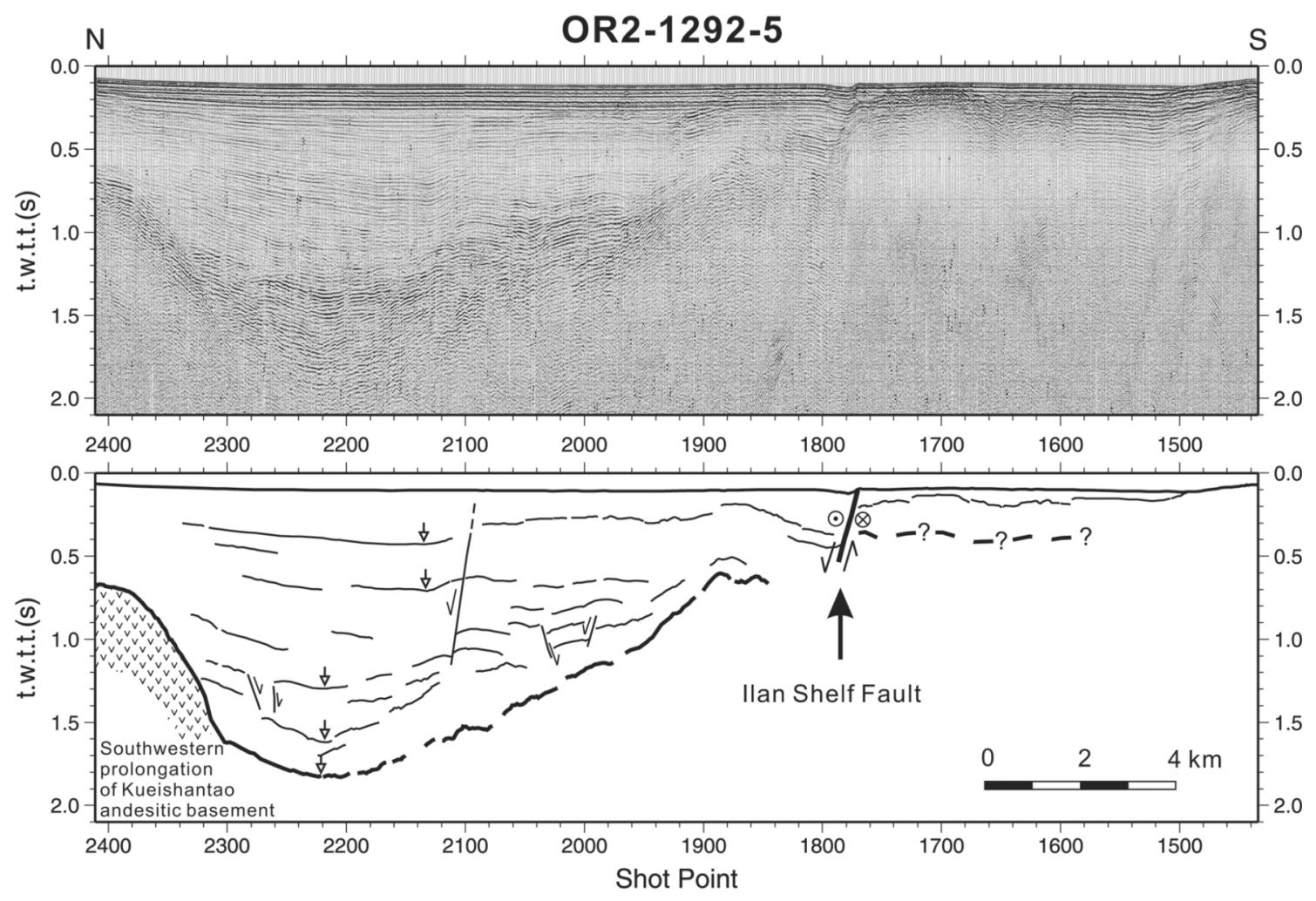

Fig. 7. S Stacked 12-channel OR2-1292-5 seismic reflection profile (top) and its interpretation (bottom). Same legend as in Figs, 3 , 4, and 5.

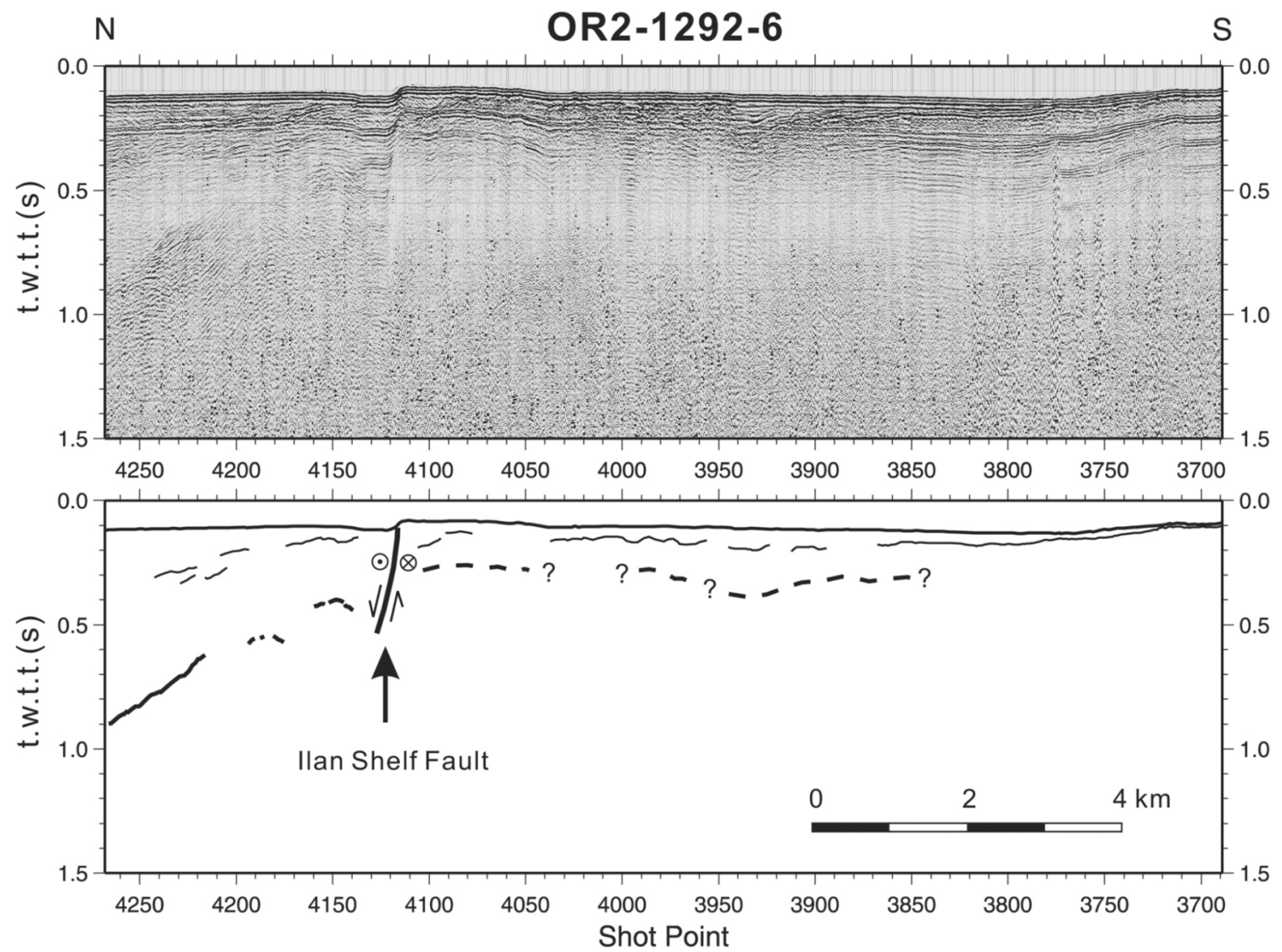

Fig. 8. Stacked 12-channel OR2-1292-6 seismic reflection profile (top) and its interpretation (bottom). Same legend as in Fig. 3. 


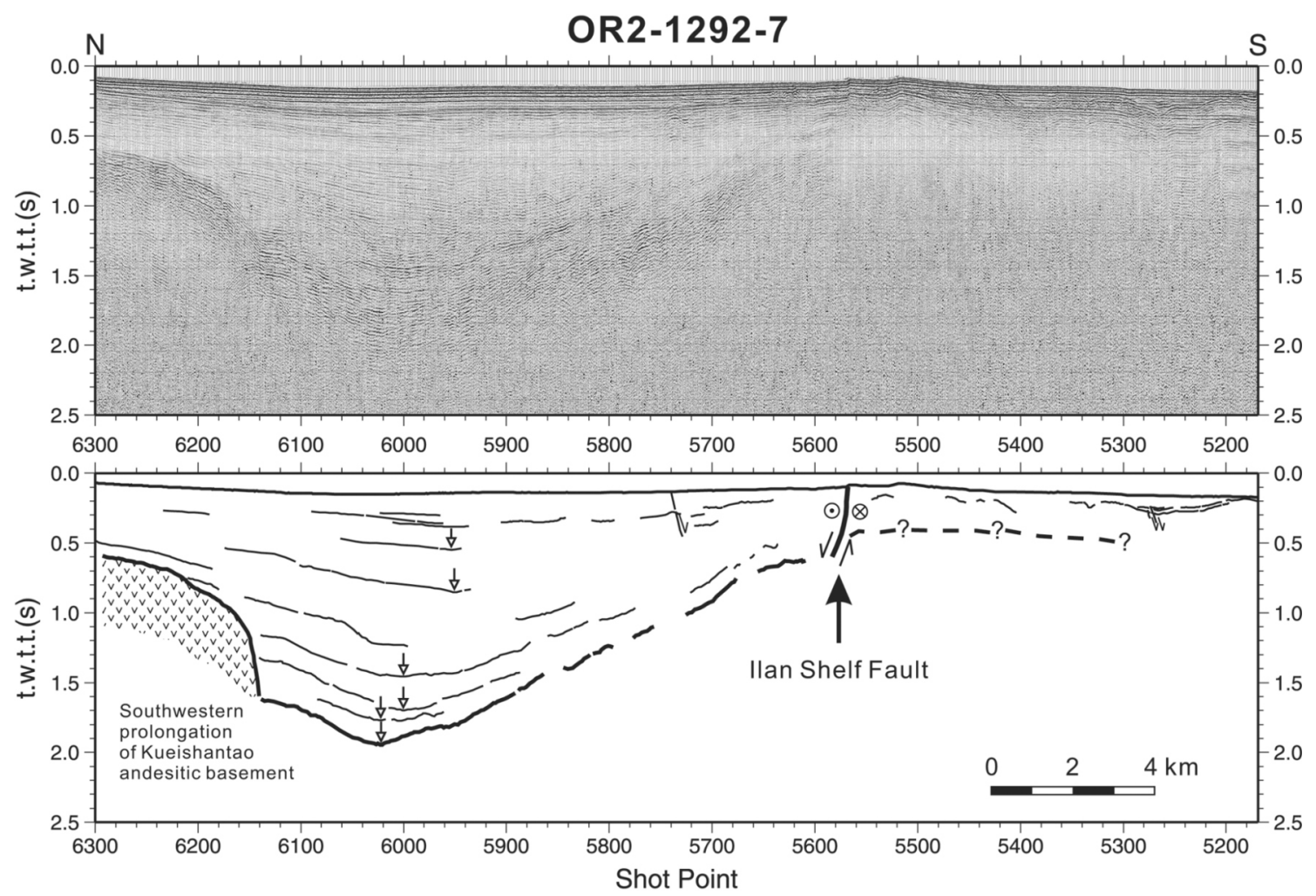

Fig. 9. Stacked 12-channel OR2-1292-7 seismic reflection profile (top) and its interpretation (bottom). Same legend as in Figs. 3, 4, and 5.

Trough depression (Fig. 10). If we take into account the interpretation of the two CPC seismic profiles onshore Ilan Plain (Chiang 1976) (Fig. 10), the location of the depocenter can be extended onland. Based on the seismic facies analysis, the high amplitude reflector is interpreted as the northern flank of the acoustic basement (Figs. 5, 7, 9). The northern flank of the Okinawa Trough basin (Fig. 10) may thus correspond to the southwestward extension of the Kueishantao Island andesitic system.

Numerous normal faults are identified in this study, but only a few (i.e., at the shot points 360 and 480 of the profile 1292-2 in Fig. 4) are detected below the acoustic basement. Most of the normal faults identified in the northern portion of the seismic profiles (where the basement is at a depth between 0.5 to $2.0 \mathrm{~s}$ t.w.t.t.) do not reach the seafloor; by contrast, those near the seafloor can be found easier in the southern portion (where the basement is at a depth between 0.1 to 0.5 s t.w.t.t.) (Figs. 3, 5, 6). It might be due to the southward migration of the sedimentary depocenters, as indicated by the white arrows in Figs. 4, 5, 7, and 9. It implies that crustal extension progressively migrated southward through time. This is also confirmed by the distribution of the present-day seismicity which mostly occurs in the southern part of the Okinawa Trough (Fig. 2).

Observed active or recently active small-scale normal faults cannot be traced from profile to profile, except for the Ilan Shelf Fault, which has been identified on all the seven seismic profiles (Figs. 3 to 9). This ENE-WSW trending fault is located south of the Okinawa Trough rift system on the northern slope of the Ilan continental shelf spur (Fig. 10). It may extend eastward along the northern flank of the continental shelf spur (Fig. 10).

As the two March 2005 earthquakes are located less than $2 \mathrm{~km}$ west of the Ilan Shelf Fault identified on seismic profiles (Fig. 10), we suggest that these two earthquakes are related to the Ilan Shelf Fault. Aftershocks of the 2005 doublet events (CWBSN catalogue) are located in the southern part of the Ilan Plain and extend along the ENE-WSW prolongation of the Ilan Shelf Fault (Fig. 10). Thus, the Ilan Shelf Fault contains both normal and left-lateral strike-slip components and extends from onshore to the offshore area. The onshore prolongation of the Ilan Shelf Fault was not seen on the two CPC reflection and refraction profiles in the Ilan Plain (Chiang 1976), this is probably due to the poor quality of the seismic profiles obtained at that time.

\section{DISCUSSION}

Figures 10 and 11a show the horizontal velocity vectors in the Ilan Plain and in Taiwan deduced from GPS measurements (Yu et al. 1997; Hou et al. 2009) with reference to the Paisha station located on the Penghu Island west of Taiwan. The velocity vectors describe the motions of a region relative to the stable Chinese continental platform. The GPS 
data were acquired from 2002 to 2006 at 34 annually surveyed geodetic sites located in the Ilan Plain region (Hou et al. 2009) (Fig. 10) and in 131 permanent stations over Taiwan recorded from 1990 to 1995 (Yu et al. 1997) (Fig. 11a). The GPS velocity field pattern in Fig. 10 differs from that shown in Fig. 11 a because of the different recording periods. Between these two GPS observations, the Chi-Chi earthquake $\left(\mathrm{M}_{\mathrm{L}}=7.3\right)$ occurred in 1999 (Ma et al. 1999) which caused an important crustal deformation in middle Taiwan (Lo and Hsu 2005). As several large earthquakes of magnitude larger than 5 occurred during the GPS recording periods, particularly in the Ilan Plain region, the measured horizontal velocity vectors reflect not only interseismic but also co-seismic displacements.

From the GPS observations in the Ilan Plain (Fig. 10), the onshore extension of the Ilan Shelf Fault roughly separates a northern region with very small eastward velocity vectors from a southern region with velocity vectors about ten times larger pointing eastward to southeastward (Fig. 10). This suggests that a large amount of left-lateral shear motion occurs along the onshore extension of the Ilan Shelf Fault. In the middle portion of the Central Range near $23.8^{\circ} \mathrm{N}$ latitude, a NW-SE trending feature separates a northern region with velocity vectors rotating clockwise relative to a southern region with the velocity vectors generally pointing towards the northwest (Fig. 11a). This NW-SE trending feature was also suggested by Hsu (2001). A pseudo-rigid block located between the Ilan Shelf Fault and the NW-SE trending feature described above is named as the "Northern Central Range" block (Fig. 12). The western boundary of the Northern Central Range block follows the Lishan Fault. The eastern boundary, however, lies offshore of eastern Taiwan (Figs. 11, 12) but is not identified in this study.

The velocity vectors located just south of the Ilan Shelf Fault (Fig. 10) changes their directions and amplitudes laterally. This means that the "Northern Central Range" block is

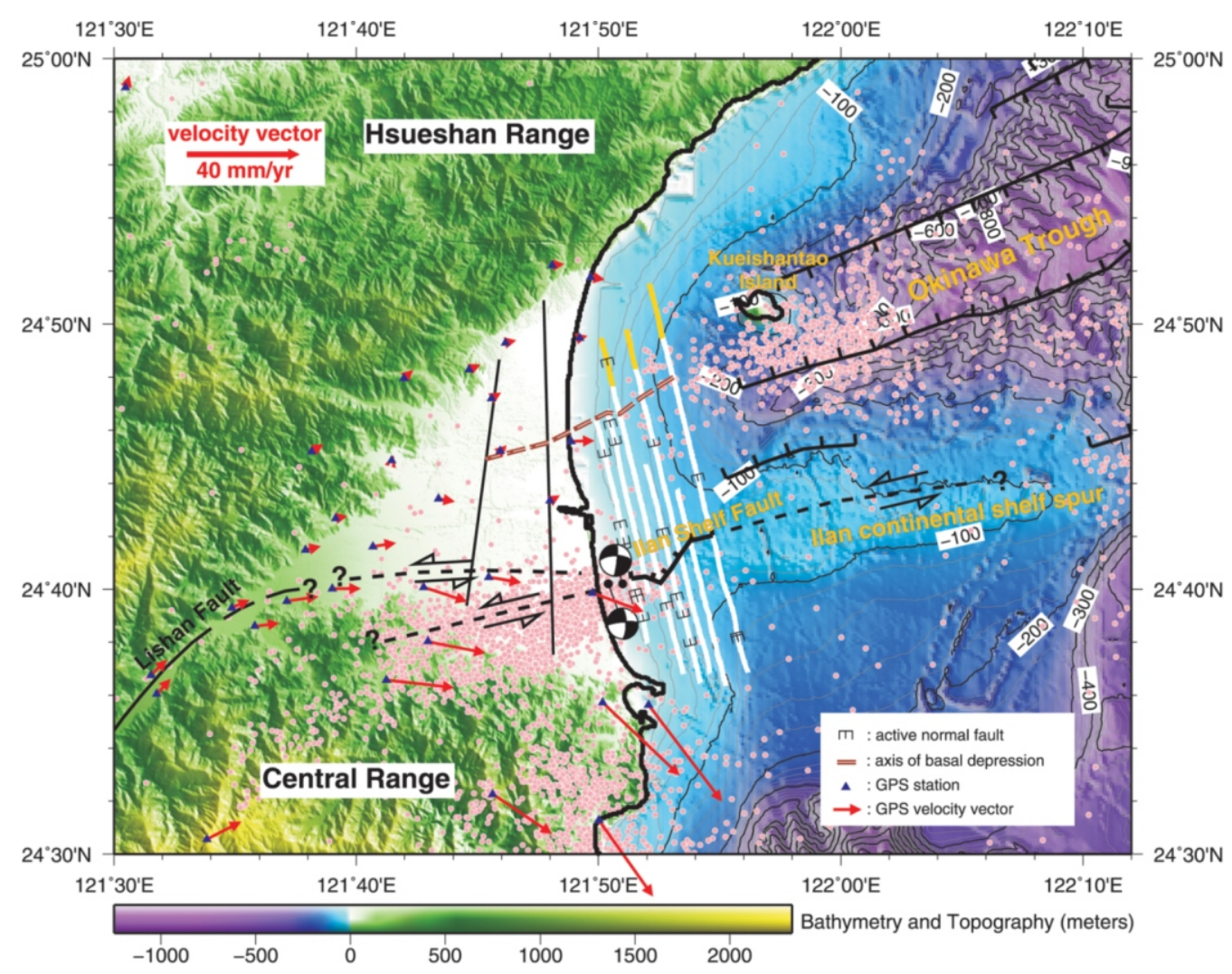

Fig. 10. GPS velocity vectors and interpreted structural features in the study area. Bathymetry contours every 100 meters. The active tectonic features are from Sibuet et al. (1998) and Deffontaines et al. (2001). Pink dots are epicenters of the earthquakes recorded in 2005 by the Central Weather Bureau (CWB) Seismic Network. White thick lines are OR2-1292 seismic reflection profiles. The yellow portions of white lines underline the southwestern prolongation of the Kueishantao Island acoustic basement. The two black lines in the Ilan Plain are the locations of the CPC seismic profiles (Chiang 1976). The dashed brown line corresponds to the axis of the basement depression. The axis is located in the prolongation of the westernmost portion of the Okinawa Trough and has been extended into the Ilan Plain on the basis of the two onland seismic profiles (Chiang 1976). The thick black line cutting across the white lines shows the location of the Ilan Shelf Fault. Based on the aftershock seismicity of the 2005 earthquake events, the dashed black line corresponds to the western prolongation of the Ilan Shelf Fault. Following the morphology of the Ilan continental shelf spur, the portion of dashed line located east of the seismic profiles corresponds to the eastern prolongation of the Ilan Shelf Fault. Black triangles and red arrows are GPS stations and velocity vectors with respect to the GPS station in Penghu Island (Hou et al. 2009). Other symbols are as in Fig. 2. 


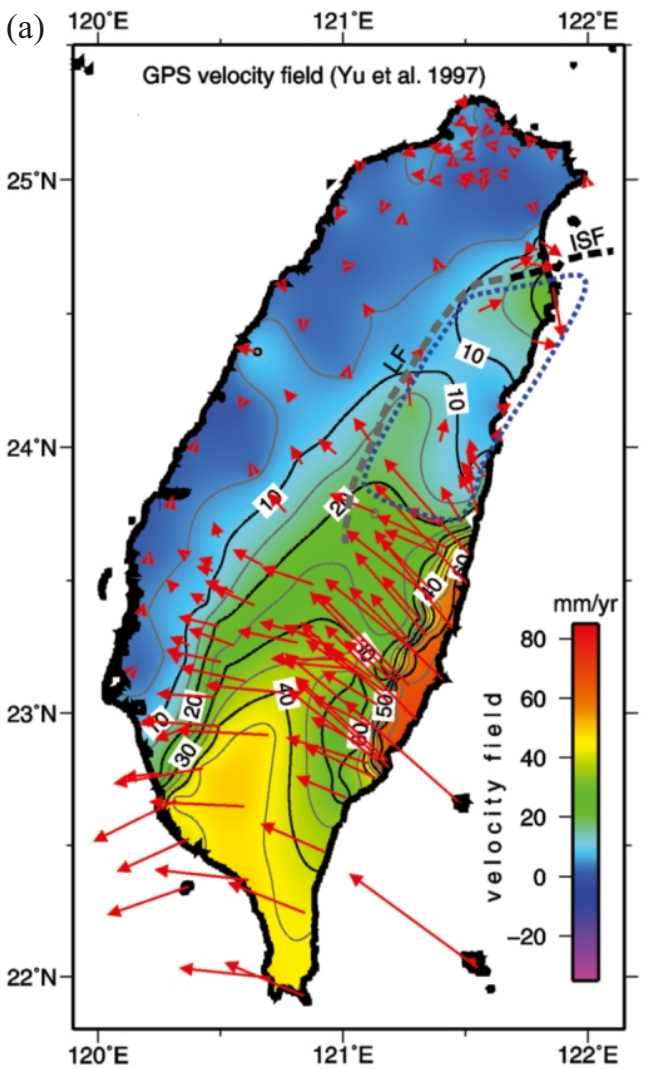

(b)

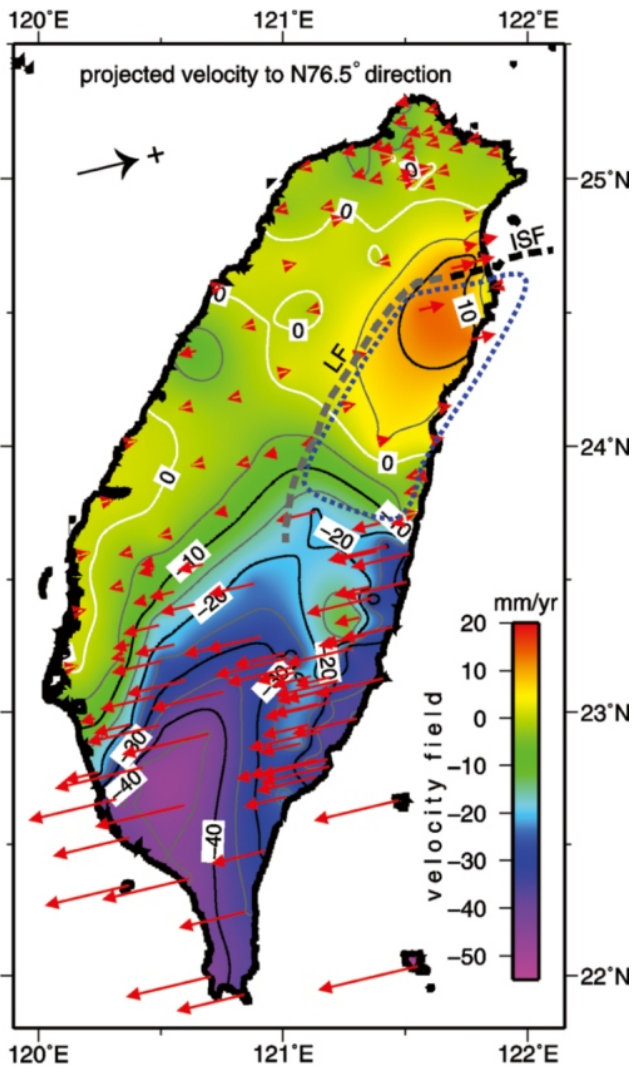

Fig. 11. GPS velocity vectors of Taiwan with $5 \mathrm{~mm} \mathrm{yr}^{-1}$ contours relative to the Paisha station in Penghu Island. (a) Smoothed GPS velocity field (Yu et al. 1997). (b) GPS velocity field derived from the measurements of Yu et al. (1997) and projected along the strike of Ilan Shelf Fault (N076.5 ${ }^{\circ}$ ). The origins of arrows are at the GPS stations. The length of each vector is proportional to the velocity. The black dashed line is the Ilan Shelf Fault (ISF). The grey dashed line is the Lishan Fault (LF). The blue dashed line shows the Northern Central Range block defined in this study.

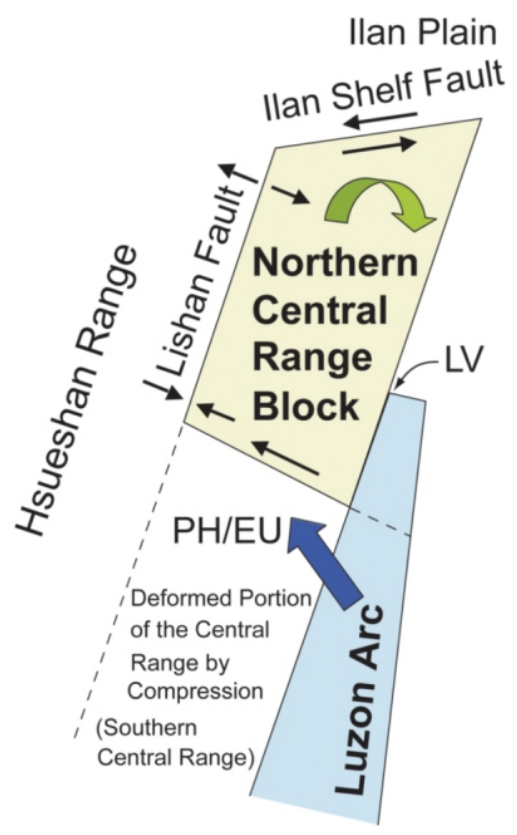

Fig. 12. A sketch showing the boundaries of the "Northern Central Range" block and relative motions along its boundaries with respect to Eurasia (EU). LV, Longitudinal Valley. The clockwise rotation of the northern Central Range block with respect to Eurasia is caused by the collision of the Luzon Arc with the Central Range. not fully rigid, or at least portions of the block located close to its boundaries are deformed due to the irregular shape of the block. The distribution of velocity vectors inside the block with respect to Penghu Island projected along the strike of the Ilan Shelf Fault (N076.5 ${ }^{\circ}$ direction) (Fig. 11b) shows that the velocity vectors point eastward in the northern part of the block and westward in the southern part of the block. It is reasonable to suggest that the block rotates clockwise with respect to the rest of the Taiwan orogen. If this is true, then there should be an extensional regime in the northern portion of the Lishan Fault, and a compressional regime in the southern portion of the Fault (Fig. 12). This interpretation is consistent with the analyses of earthquake focal mechanisms conducted by Yeh et al. (1991). In addition, Lee et al. (1997) also suggested that back-thrusting occurs further south along the Lishan Fault as a combination of Quaternary uplifting of the Hsueshan Range and horizontal compression. Thus, the southern Hsueshan Range is highly deformed by contraction in the northwestern direction (Fig. 11a) due to a "lock" or a "collision" in the southern part of the block. We suggest that the clockwise rotation of the northern Central Range block is probably due to the $\mathrm{N} 309^{\circ}$ motion of the Luzon Arc against the Eurasia plate. In that case, the 
northeastern end of the northern Central Range block should have pulled apart from the Okinawa Trough and created an extensional normal faulting component. That is why we can observe normal faulting along the Ilan Shelf Fault. Another explanation is that the northern Central Range block could have been tilted northward that could also create a normal faulting component along the Ilan Shelf Fault.

To summarize, the impinging Luzon Arc colliding with Eurasia continental margin along the $\mathrm{N} 309^{\circ}$ direction has caused the clockwise rotation of the northern Central Range block, giving rise to a lateral extrusion of the northern portion of the block along the Ilan Shelf Fault. In this scheme, the Ilan Shelf Fault is considered the southern boundary of the Okinawa Trough extensional system. The left-lateral motion along the Ilan Shelf Fault results from the clockwise rotation of the northern Central Range block. As the Ilan Shelf Fault is located south of the Ilan Plain, this left-lateral motion may favor a propagation of the western tip of the Okinawa Trough into Taiwan. According to Sibuet et al. (2004), the western tip of the Okinawa Trough has remained approximately above the edge of the Ryukyu slab through time. As the Ryukyu Islands moved westward at a mean velocity of $4.5 \mathrm{~cm} \mathrm{yr}^{-1}$ in the last $9 \mathrm{Ma}$ (Sibuet et al. 2004), the westward propagation of the Okinawa Trough might also proceed at the same velocity. The clockwise rotation of the northern Central Range block and the rifting mechanism of the Okinawa Trough provide a simple interpretation for the triangular shape of the Ilan Plain. In other words, the southwestern Okinawa Trough consists of N-S normal faulting extension and left-lateral motion along the Ilan Shelf Fault.

\section{CONCLUSION}

Seven seismic reflection profiles have been collected in the offshore area of the Ilan Plain to investigate the relationship between the ENE-WSW trending normal faults of the westernmost portion of the Okinawa Trough and the existence of a cluster of ENE-WSW trending earthquakes in the southern part of the Ilan Plain. A major ENE-WSW trending fault with a significant normal faulting component named the Ilan Shelf Fault has been identified on each of the collected seismic profiles. By integrating the information gleaned from seismic and GPS data, we suggest that the Ilan Shelf Fault is a structural fault with a normal faulting component as well as a left-lateral strike-slip component, which extends from the Ilan Plain to the Ilan continental shelf spur and beyond. The Ilan Shelf Fault is considered to be the boundary between the southern tip of the Okinawa Trough backarc basin and the northern Central Range block. The Ilan Shelf Fault is probably produced by a clockwise rotation of the "northern Central Range" block associated with the northwestward collision of the Luzon Arc against the Eurasian continental margin.
Acknowledgements We appreciate fruitful discussions with Drs. Chien-Ying Wang, Wen-Tzong Liang, and JyrChing $\mathrm{Hu}$. We are indebted to Prof. Char-Shine Liu and Dr. Jian-Cheng Lee for their fruitful reviews. We appreciate Editor Chih-An Hun's aid in greatly improving our manuscript. This study was supported under a grant of the National Science Council, Taiwan. Mr. Shye-Donq Chiou from Institute of Oceanography, National Taiwan University, Taiwan, helped collect the multichannel seismic reflection data used in this study. J. C. Sibuet acknowledges the National Taiwan Ocean University as a visiting chair professor.

\section{REFERENCES}

Chen, C. H., T. Lee, Y. N. Shieh, C. H. Chen, and W. Y. Hsu, 1995: Magmatism at the onset of back-arc basin spreading in the Okinawa Trough. J. Volcanol. Geoth. Res., 69, 313322, doi: 10.1016/0377-0273(95)00028-3. [Link]

Chiang, H. C., 1976: Seismic study in the Ilan Plain. Mining Technology, 14, 215-221. (in Chinese)

Chung, S. L., S. L. Wang, R. Shinjo, C. S. Lee, and C. H. Cheng, 2000: Initiation of arc magmatism in an embryonic continental rifting zone of the southernmost part of Okinawa Trough. Terr. Nova, 12, 225-230, doi: 10.1046/j.13653121.2000.00298.x. [Link]

Deffontaines, B., C. S. Liu, J. Angelier, C. T. Lee, J. C. Sibuet, Y. B. Tsai, S. Lallemand, C. Y. Lu, C. S. Lee, S. K. Hsu, H. T. Chu, J. C. Lee, E. Pathier, R. F. Chen, C. T. Cheng, C. W. Liao, and H. H. Hsu, 2001: Preliminary neotectonic map of onshore-offshore Taiwan. Terr. Atmos. Ocean. Sci., Supplementary Issue, 339-349.

Hou, C. S., J. C. Hu, K. E. Ching, Y. G. Chen, C. L. Chen, L. W. Cheng, S. H. Huang, and C. H. Lo, 2009: The crustal deformation of the Ilan Plain acted as a westernmost extension of the Okinawa Trough. Tectonophysics, 466, 344355, doi: 10.1016/j.tecto.2007.11.022. [Link]

Hsu, S. K., 2001: Subduction/collision complexities in the Taiwan-Rykyu junction area: Tectonics of the northwestern corner of the Philippine Sea plate. Terr. Atmos. Ocean. Sci., Supplementary Issue, 209-230.

Hsu, S. K., J. C. Sibuet, and C. T. Shyu, 1996: High-resolution detection of geologic boundaries from potential-field anomalies: An enhanced analytic signal technique. Geophysics, 61, 373-386, doi: 10.1190/1.1443966. [Link]

Lee, C. S., J. Shor, L. D. Bibee, R. S. Lu, and T. W. C. Hilde, 1980: Okinawa Trough: Origin of a back-arc basin. Mar. Geol., 35, 219-241, doi: 10.1016/0025-3227(80)90032-8. [Link]

Lee, J. C., J. Angelier, and H. T. Chu, 1997: Polyphase history and kinematics of complex major fault zone in the Taiwan mountain belt: The Lishan Fault. Tectonophysics, 274, 97-115, doi: 10.1016/S0040-1951(96)00300-9. [Link]

Liang, W. T., J. C. Lee, and B. Y. Kuo, 2005: Left-lateral strike-slip faulting in Ilan: Lateral extrusion at the transi- 
tion between Taiwan Mountain Range and the Okinawa Trough. Geodynamics and Environment in Asia International Conference and $5^{\text {th }}$ Taiwan-France Earth Science Symposium, Abstract, 104-108.

Lin, J. Y., S. K Hsu, and J. C. Sibuet, 2004: Melting features along the western Ryukyu slab edge (northeast Taiwan): Tomographic evidence. J. Geophys. Res., 109, B12402, doi: 10.1029/2004JB003260. [Link]

Lo, C. L. and S. K. Hsu, 2005: Earthquake-induced gravitational potential energy change in the active Taiwan orogenic belt. Geophys. J. Int., 162, 169-176, doi: 10.1111/ j.1365-246X.2005.02634.x. [Link]

Ma, K. F., C. T. Lee, Y. B. Tsai, T. C. Shin, and J. Mori, 1999: The Chi-Chi, Taiwan earthquake: Large surface displacements on an inland thrust fault. $E O S, \mathbf{8 0}, 605-611$, doi: 10.1029/99EO00405. [Link]

Sibuet, J. C, J. Letouzey, F. Barbier, J. Charvet, J. P. Foucher, T. W. C. Hilde, M. Kimura, L. Y. Chiao, B. Marsset, C. Muller, and J. F. Stéphan, 1987: Back arc extension in the Okinawa Trough. J. Geophys. Res., 92, 14041-14063, doi: 10.1029/JB092iB13p14041. [Link]

Sibuet, J. C., B. Deffontaines, S. K. Hsu, N. Thareau, J. P. Le
Formal, C. S. Liu, and ACT party, 1998: Okinawa Trough backarc basin: Early tectonic and magmatic evolution. $J$. Geophys. Res., 103, 30245-30267, doi: 10.1029/98JB 01823. [Link]

Sibuet, J. C., S. K. Hsu, and E. Debayle, 2004: Geodynamic context of the Taiwan orogen. In: Clift, P., P. Wang, W. Kuhnt, and D. Hayes (Eds.), Ocean-Continent Interactions in the East Asian Marginal Seas, Geophys. Monogr., 149, 127-158.

Wang, C. S., M. L. Yang, C. P. Chou, Y. C. Chang, and C. S. Lee, 2000: Westward extension of the Okinawa Trough at its western end in the northern Taiwan area: Bathymetric and seismological evidence. Terr. Atmos. Ocean. Sci., 11, 459-480.

Yeh, Y. H., E. Barrier, C. H. Lin, and J. Angelier, 1991: Stress tensor analysis in the Taiwan area from focal mechanisms of earthquakes. Tectonophysics, 200, 267-280, doi: 10.1016/0040-1951(91)90019-O. [Link]

Yu, S. B., H. Y. Chen, and L. C. Kuo, 1997: Velocity field of GPS stations in the Taiwan area. Tectonophysics, 274, 41-59, doi: 10.1016/S0040-1951(96)00297-1. [Link] 